ALMEIDA, Darcy Fontoura de. A contribuição de Carlos Chagas Filho para a institucionalização da pesquisa científica na universidade brasileira. História, Ciências, Saúde - Manguinhos, Rio de Janeiro, v.19, n.2. abr.-jun., p.653-668.

\title{
Resumo
}

Estuda o período considerado a 'pré-história' do Instituto de Biofísica, entre novembro de 1937 e outubro de 1945, durante o qual Carlos Chagas Filho buscou a implantação da pesquisa científica na Universidade do Brasil

\section{A contribuição de Carlos Chagas Filho para a institucionalização da pesquisa científica na universidade brasileira}

\section{The contribution of Carlos Chagas Filho to the institutionalization of scientific research in Brazilian universities}

\author{
Darcy Fontoura de Almeida \\ Professor emérito da Universidade Federal do Rio de Janeiro \\ Av. Rui Barbosa 830/1102 \\ 22250-020 - Rio de Janeiro - RJ - Brasil \\ darcyalmeida@terra.com.br
}

Recebido para publicação em setembro de 2010.

Aprovado para publicação em fevereiro de 2011.
(UB), apesar dos múltiplos e complexos obstáculos. A inexistência de precedentes de sucesso na UB isolava-o numa cadeira básica. $\mathrm{O}$ equipamento disponível era inadequado para seus fins, não existiam fontes oficiais e formais de auxílio à ciência nem pessoal preparado para atividades de pesquisa. Por outro lado, Chagas Filho conquistou aliados devido tanto à força político-social de seu nome e de seu casamento, quanto à influência científica decorrente de seu êxito na finalidade a que se propôs.

Palavras-chave: Carlos Chagas Filho (1910-2000); Instituto de Biofísica; pesquisa na universidade; Brasil.

\section{Abstract}

This paper studies the period considered the 'prehistory' of the Instituto de Biofisica, namely between November 1937 and October 1945, during which Carlos Chagas Filho championed the inclusion of scientific research at Universidade do Brasil (UB), despite facing multiple and complex obstacles. The lack of successful precedents at UB isolated him to one inexpressive chair. The equipment available was inadequate for his purposes; there were no official sources and forms of access to funding for science or trained personnel for research activities. On the other hand, Chagas Filho won over allies due both to the political and social clout of his name and his marriage, and to his scientific influence ensuing from his success in attaining the goals he fought for.

Key words: Carlos Chagas Filho (19102000); Instituto de Biofísica; university research; Brazil. 

mestre, companheiro e amigo.

O presente trabalho se propõe examinar o processo de institucionalização da pesquisa científica na universidade brasileira e o papel nele desempenhado por Carlos Chagas Filho. Será adotado, como caso de estudo, o Laboratório de Biofísica (LB) da Universidade do Brasil (UB), que, superposto à cadeira de física biológica, foi criado extraoficialmente por Chagas Filho e perdurou do final de 1937 a 1945. Laboratório e cadeira foram superados pelo Instituto de Biofísica (IB), criado pelo decreto 8.393, de 17 de dezembro de 1945, que concedeu autonomia à UB. Lidaremos, portanto, com a 'pré-história' do IB, com as raízes que possibilitaram a existência da instituição. Não cuidaremos aqui da ciência praticada em instituições isoladas, de natureza vária (museus, institutos etc.), antes do aparecimento da primeira universidade brasileira, a Universidade do Rio de Janeiro (URJ), em 1920.

Serão abordadas as iniciativas de Carlos Chagas Filho (1910-2000) para que a cadeira de física biológica da URJ fosse convertida em instituto universitário de pesquisa e, em decorrência, centro de ensino da biofísica e ciências afins. Como integrantes de contexto mais amplo, serão também examinados e discutidos imprevistos, circunstâncias e contingências que, direta ou indiretamente, contribuíram para a fundação do IB.

Para fins de definição, é também indispensável esclarecer que não nos será possível cuidar, com o detalhe de que seriam merecedoras, de duas importantes e valiosas obras contemporâneas daquela desenvolvida por Chagas Filho: a Universidade de São Paulo (USP), de 1934, e a Universidade do Distrito Federal (UDF), de 1935. Não quer isso dizer que serão elas ignoradas no texto, mesmo porque tiveram ambas, especialmente a primeira, destacadas e positivas interações com o trajeto científico de Chagas Filho.

\section{A criação da universidade no Brasil}

Apontada por tantos analistas não só como de chegada retardada, mas também como de inadequada concepção, a criação da URJ, na prática, teve sua organização autorizada pelo decreto 11.530, de 18 de março de 1915, a chamada reforma (Carlos) Maximiliano. Em seu artigo 6o, prescrevia o decreto que "O Governo Federal, quando achar oportuno, reunirá em Universidade as Escolas Politécnica e de Medicina do Rio de Janeiro, incorporando a elas uma das Faculdades Livres de Direito ..." (Brasil, 18 mar. 1915).

A data escolhida para a materialização da URJ, primeira universidade brasileira "de vida longa" (Cunha, 2007, p.190), por meio do decreto 14.343, foi o dia 7 de setembro de 1920 (Brasil, 7 set. 1920). Antes e depois da URJ, experiências com finalidade semelhante não foram bem-sucedidas e, por isso, são consideradas "de vida curta" (Cunha, 2007).

O primeiro reitor da URJ, professor Ramiz Galvão (1846-1938), enviou em 1921 relatório ao ministro de Estado e Negócios da Justiça, Joaquim Ferreira Chaves (1852-1937), no qual analisa o desempenho da universidade em seu primeiro ano de vida. Parte desse documento é reproduzida no atual site oficial da instituição: 


\begin{abstract}
a Universidade do Rio de Janeiro está apenas criada in nomine, e por esta circunstância se acha longe de satisfazer o desideratum do seu Regimento: estimular a cultura das ciências, estabelecer entre os professores laços de solidariedade intelectual e moral, e aperfeiçoar os métodos de ensino. Constituída pela agregação das três faculdades preexistentes, de Engenharia, de Medicina e de Direito, do Rio de Janeiro, nem, ao menos, têm elas a sua localização comum ou próxima. Vivem apartados e alheios uns aos outros os três institutos que a compõem, sem laço de ligação, além do Conselho Universitário, cujos membros procedem das três Faculdades (Galvão citado em UFRJ, s.d.).
\end{abstract}

São numerosas as análises históricas de teor semelhante, o que nos parece não deixar dúvida a respeito da impropriedade daquela iniciativa. Matéria de maior significado para o presente trabalho, por se referir à função de pesquisar e daí então ensinar na universidade, é considerada por Cunha (2007, p.18) em A universidade temporã. Ao discutir "o lamento da universidade tardia no Brasil", oferece ele critério unificador para o ensino superior, assim definido: "o ensino superior é aquele que visa ministrar um saber superior". A seguir, classifica os saberes em função das classes sociais, dominantes e dominados, e acrescenta: "Não se deve pensar, entretanto, que essa função de ensinar um saber dominante se faz sem contradições. O próprio conteúdo do ensino, mesmo enquadrado no saber dominante, pode contribuir para dissolver esse saber e as relações que o colocam em posição dominante." Em outras palavras, poderíamos admitir que tais acontecimentos determinassem uma mudança nos compromissos daquele saber. Afirma Thomas Kuhn (1922-1996), ao se referir ao progresso da ciência: "Os episódios extraordinários [fora da ciência 'normal'] ... que produzem tais mudanças podem ser designados ... como 'revoluções'. ... Seriam complementos rompedores da tradição no interior da atividade dita 'normal' ou 'tradicional'" (Kuhn, 1962, p.66-76). ${ }^{1}$

A função de ensinar (e não apenas a função de pesquisar), portanto, deve gerar contradições e passa a ser vista como uma das mais nobres propriedades do ensino superior/ dominante. O ponto de vista de Chagas Filho, exposto anos mais tarde, coincidia ou, pelo menos, se achava muito próximo dessa formulação: tanto a busca quanto as conjunturas das contradições se encontram na vanguarda do saber. Essa função científica da universidade brasileira viria a ser finalmente valorizada na década de 1930.

\title{
A evolução do processo de institucionalização da pesquisa na universidade brasileira
}

Para analisar esse processo, usaremos como referências dados básicos dos dois exemplos mais marcantes de universidades aparecidas no Brasil durante a década de 1930. Em primeiro lugar, a USP (fundada em 1934), reconhecida como a entidade pioneira na implantação da pesquisa científica na universidade brasileira. "Ao se criar a Universidade de São Paulo, ... o governo paulista dispunha de seis instituições de ensino superior, públicas ou privadas, em franca produção científica, profissional e magisterial, que se fundiram no conjunto universitário. ... E a Faculdade de Filosofia, Ciências e Letras (FFCL) foi agente dos mais eficazes nesse processo" (Campos, 1954, p.69).

O decreto 6.283, de 25 de janeiro de 1934, que criou a USP dispõe, em seu título I, artigo 2:: "São fins da Universidade: a) promover, pela pesquisa, o progresso da ciência; b) transmitir, 
pelo ensino, conhecimentos que enriqueçam ou desenvolvam o espírito ou sejam úteis à vida" (São Paulo, 25 jan. 1934).

A derrota do movimento constitucionalista de 1932 provocou resposta da oligarquia cafeeira - associada aos intelectuais e às classes dirigentes paulistas e catalisada pelo grupo diretor do jornal O Estado de S. Paulo -, que se materializou na criação da USP. A universidade como centro de pesquisas científicas, além de formadora de competentes professores do ensino médio, foi caminho bem escolhido para atingir o alvo pretendido, qual seja a constituição de uma nova classe dirigente. São outras marcas distintivas da USP a centralização integradora exercida pela Faculdade de Filosofia, Ciências e Letras e o trabalho em regime de dedicação exclusiva. ${ }^{2}$

Imediatamente após a USP, surgiu a Universidade do Distrito Federal (UDF), em 1935, fenômeno municipal e sonho, projeto e realização de Anísio Spínola Teixeira (1900-1971), cooptado por considerável grupo de intelectuais. Ao pronunciar, na qualidade de reitor da UDF, seu discurso de inauguração dos cursos, em 31 de julho de 1935, Anísio mal imaginava que estava a nos legar um dos documentos mais dramáticos da história da educação nacional. Aqui vão duas passagens contrastantes do discurso: a primeira é um belo canto de esperança, repetido aqui, agora, após numerosas citações ao longo da historiografia da educação superior nacional; logo a seguir, a outra é um profético lamento que antecipa o triste futuro reservado à UDF. A esperança:

A função da universidade é uma função única e exclusiva. Não se trata somente de difundir conhecimentos. O livro também os difunde. Não se trata, somente, de conservar a experiência humana. O livro também a conserva. Não se trata, somente, de preparar práticos ou profissionais de ofícios ou artes. A aprendizagem direta os prepara, ou, em último caso, escolas muito mais singelas do que universidades.

Trata-se de manter uma atmosfera de saber, para se preparar o homem que o serve e o desenvolve. Trata-se de conservar o saber vivo e não morto, nos livros ou no empirismo das práticas não intelectualizadas. Trata-se de formular intelectualmente a experiência humana, sempre renovada, para que a mesma se torne consciente e progressiva....

O saber não é um objeto que se recebe das gerações que se foram para a nossa geração; o saber é uma atitude de espírito que se forma lentamente ao contato dos que sabem (Teixeira, 1998, p.87-88).

O lamento:

E qual a universidade que abre, hoje, aqui as suas portas? ... É uma universidade cujas escolas visam o preparo do quadro intelectual do país, que até hoje se tem formado ao sabor do mais abandonado e mais precário autodidatismo. ... A crítica não tinha como ser mais infeliz. Não podia morrer, entretanto, a malevolência dos que se obstinam em não deixar o país progredir para que possam continuar a viver à custa dele, na sua meia ignorância. Já agora, a UDF podia ser útil e até necessária, mas devia fechar-se porque desobedecia aos padrões de uma lei federal do período discricionário, tacitamente derrogada pela Constituição Federal (p.92-93).

Frustrou-se a esperança. O lamento tornou-se realidade ou, no dizer de Fávero (1980), uma utopia vetada: a UDF teve fechadas suas portas em 1939 e terminaria por ser incorporada à planejada Faculdade Nacional de Filosofia. ${ }^{3}$ 


\section{A original participação da cadeira de física biológica da Universidade do Rio de Janeiro na institucionalização da pesquisa na universidade e a importância da escolha do modelo experimental}

A partir deste ponto não mais cuidamos de universidades que se organizavam como um todo; descemos a pirâmide hierárquica do ensino superior até o nível das disciplinas isoladas. Isoladas, aliás, bem caracteriza o estado das relações internas entre as diferentes unidades acadêmicas, ao serem apenas esboçadas as primeiras universidades no país, no início do século XX. O acontecido com Álvaro Ozório de Almeida (1882-1952) é paradigmático da época. Ao regressar de estágio em laboratórios do Instituto Pasteur, na França, pretendia ele implantar um projeto de pesquisa na Faculdade de Medicina (Almeida, 2008). Thales Martins (1896-1979) dá seu depoimento a respeito:

Podemos imaginar, de volta da Europa, quantas ideias de trabalho não arquitetava; e a ducha de água fria da volta à realidade, em meio à indiferença, senão hostilidade, para quem, entre nós, se desse ao luxo de querer criar ciência. Sem desanimar, principiou, como Cajal (1852-1934), em casa, [num] pequeno laboratório mantido em parte por Candido Gaffrée, e improvisado no porão da rua Almirante Tamandaré (Martins, citado em Almeida, 1950, p.2).

Chegamos assim ao objeto maior do presente trabalho, a cadeira de física biológica da Faculdade de Medicina da URJ, denominação em vigor até 5 de julho de 1937, quando a URJ foi substituída pela UB. Há importante e evidente distinção entre os casos até aqui citados e esse novo. Trataremos agora não mais de uma universidade, mas de uma cadeira no interior de uma faculdade. Na prática, há particulares adicionais que acentuam tal diferença, em especial nos anos 1930. É o que ocorre com nosso personagem central, Carlos Chagas Filho (30 set. 1936). Apesar de haver feito sua opção em favor da cátedra, declarava, convicto, ter sido 'um produto de Manguinhos' (Chagas Filho, 1940, 1988; Almeida, 2008).

O depoimento de Thales Martins, associado a essa definição pessoal de Chagas Filho (Almeida, 2008), reforça e torna mesmo mais compreensível sua preferência por uma "casa da ciência" bem-sucedida, em desfavor de um lócus acadêmico pouco atraente. As razões para que Chagas Filho mudasse, na aparência, sua opção de trabalho vão desde a convivência próxima - pessoal e de trabalho - com pesquisadores experimentados, nacionais e estrangeiros, em Manguinhos, até a tônica genérica da falta de atrativos maiores no curso médico. Esses e outros fatores, associados às brilhantes carreiras do pai e do irmão, já foram alvo de análise (Chagas Filho, 1987-1988; Almeida, 2008, p.269-272).

Para nossos propósitos agora, bastaria acentuar a inusitada e rápida sucessão de eventos na carreira universitária de Chagas Filho, que o alçaram da simples posição de assistente à de catedrático de física biológica da Faculdade Nacional de Medicina (FNM), da UB. ${ }^{4}$

Chagas Filho foi empossado como catedrático em 23 de novembro de 1937. Seu discurso de posse foi cauteloso, como convinha ao mais jovem membro (27 anos de idade) dos conselhos superiores de uma instituição que, tal como já descrito, não demonstrava muita simpatia pelo desenvolvimento de projetos de pesquisa em suas instalações. Foi prudente sem se acovardar (Almeida, 2003, p.142-143); disse o que pensava, mas a fala que usou tomou-a emprestada de seu pai, ao declarar: "não excluirei do ensino a pesquisa" (Chagas Filho, 23 nov. 1937). 
Tomado por incoercível urgência, lançou mão de todos os recursos de que dispunha, recebeu auxílio do sogro e partiu com sua mulher, Ana Leopoldina de Mello Franco (Annah, para os familiares), em viagem à França e à Inglaterra que, caso tivesse sido adiada, só se poderia realizar no pós-guerra. Chagas Filho jantava com Edgar Adrian, futuro lorde Adrian (1889-1977), na Universidade de Cambridge, quando recebeu a notícia da invasão da Áustria pelos alemães, em 11 de março de 1938 (Chagas Filho, 2000, p.84). Iniciava-se a Segunda Guerra Mundial, e parelha ocasião para viagem como essa não surgiria antes de 1945, com o final do conflito (Almeida, 2003). Menos mal: a visita que fizeram foi riquíssima em eventos cujas consequências repercutiram por todo o sempre na vida do casal e, sobretudo, na carreira científica de Chagas Filho.

O relato detalhado dessa viagem nos foi deixado por Chagas Filho (2000, p.93-138) em seu último livro. Pela primeira vez trabalhou ele lado a lado com cientistas de reconhecido valor, em laboratórios estrangeiros perfeitamente equipados para os fins a que se destinavam. Assim, viveu o dia a dia de laboratórios famosos. Da mesma forma, nos encontros com grandes nomes da ciência internacional, tornou-se conhecido, para o que muito contribuiu seu próprio nome. Em Paris, ao frequentar o Institut de Biologie Physico-Chimique (IBPC), estabeleceu relações profissionais e de amizade para toda a vida com René (1890-1993) e Sabine Wurmser (ca.1909-2001). Em sua autobiografia, aliás, Chagas Filho (2000, p.80) menciona esse encontro: "Wurmser ... veio a se tornar um dos meus maiores amigos e, em muitos aspectos, meu mentor científico". O laboratório de Wurmser, no segundo andar do IBPC, era vizinho do laboratório de Fauré-Frémiet (1883-1971), que também muito influenciou a carreira científica de Chagas Filho (2000, p.38; Almeida, 2003, p.137-138).

Nos laboratórios de Alfred Fessard (1900-1982) e Denise Albe-Fessard (1916-2003), no Institut Marey, ao assistir a seminário de Daniel Auger (1900-1940) sobre a bioeletrogênese em raia do gênero Torpedo, Chagas Filho teve a percepção daquele que viria a ser o modelo autóctone (materializado mais tarde no Electrophorus electricus) que buscava para sua pesquisa. Em entrevista a Virginia Schall (2001, p.163-164), ele descreve o acontecimento:

Como é que eu fui me interessar por peixe elétrico? É o seguinte: eu fui para Paris logo que tirei [sic] a cátedra. Chegando lá, num seminário [no laboratório dos Fessard], ... vi o que era um torpedo, ... um peixe-elétrico de água salgada. E fiquei interessadíssimo por ele. ... Quando cheguei aqui ... pensava em escolher como tema ... um modelo local. E eu fiquei na dúvida entre a preguiça e o peixe-elétrico. A preguiça eu deixei em pouco tempo, porque era muito difícil de capturar, difícil de manter no biotério, mais perigosa do que o peixe elétrico. ... Eu achei que o poraquê era o modelo ideal para a biofísica - porque transforma a energia química do órgão elétrico em energia elétrica da descarga. Que é exatamente um dos objetivos da biofísica, o estudo das transformações energéticas.

Estava resolvido o problema do modelo: seria o poraquê do Amazonas.

Os pontos altos de sua visita à Inglaterra foram a Universidade de Cambridge e os encontros com o prêmio Nobel de 1932, de Fisiologia ou Medicina, lorde Adrian, que mais tarde participaria da celebração do 25ㅇ aniversário do IB. Também usufruiu da hospitalidade de Archibald V. Hill (1886-1977; prêmio Nobel de Fisiologia ou Medicina, 1922), no University College, em Londres, de onde trouxe a observação básica do valor da união e atuação solidária de toda a equipe, em qualquer nível de participação, nas pesquisas em curso. 
O confronto entre as atividades e instalações europeias e as de seu próprio laboratório resultou em choque altamente positivo para o comportamento de Chagas Filho no futuro imediato, como catedrático de biofísica da FNM. Além da inspiração para o modelo de pesquisa, fatores críticos foram identificados, como o caráter obsoleto de seus equipamentos e sua impropriedade, mais indicados que eram para o ensino de física básica. Havia muito a fazer, mas os fundos necessários eram praticamente inexistentes. Acima de tudo, faltavalhe ainda pessoal capacitado para exercer as diferentes funções inerentes ao laboratório que desejava criar.

Não haverá, contudo, exagero em supor que a maior lição recebida então por Chagas Filho tenha sido a da absoluta necessidade de interação permanente com pesquisadores e laboratórios mais avançados, no exterior. Esse mandamento é facilmente reconhecível não só em sua própria trajetória, como também no processo de formação de estudantes que orientou a partir dos cursos de graduação.

\section{A fundação do Laboratório de Biofísica: em busca de pessoal}

Após o término da viagem à Europa, surgiu o LB, equivalente à cadeira de física biológica. Seus espaços, suas instalações, seus membros constituintes, com todo seu equipamento e tudo o mais, eram rigorosamente os mesmos, com uma importante diferença: a cadeira era instituição oficial reconhecida; o LB, área não formalizada, diretamente ligada à presença de Chagas Filho, seu criador - embora essa denominação fosse utilizada até mesmo em correspondência oficial.

A mudança efetuada nos traz à lembrança fato semelhante ocorrido na história do Instituto Oswaldo Cruz (IOC), relatado com minúcias por Henrique Aragão (1879-1956):

Ocorreu então qualquer coisa de muito insignificante na aparência, mas na realidade de decisiva importância nos fastos da Medicina Experimental no Brasil. Num desses trabalhos publicados em 1901, sobre $A$ vacinação antipestosa, Oswaldo Cruz (1872-1917) colocou a seguinte indicação de origem logo abaixo do título e do nome do autor: "Trabalho do Instituto Soroterápico Federal (Instituto de Manguinhos)" e, na sua primeira página, ... a seguinte dedicatória ...: "Ao Exmo. Sr. Barão de Pedro Affonso - Fundador e Diretor do Instituto de Manguinhos" (Aragão, 2000).

Aragão (2000) oferece uma segunda leitura para esse texto. A mudança do nome da instituição para Instituto de Manguinhos, acrescida da dedicatória ao barão, esconderia uma mensagem: "uma revelação a todos de que Oswaldo Cruz ia lançar-se ... na luta para a realização do magnífico programa que se traçara e que até então mantivera em segredo, de dotar, um dia, o Brasil de uma prestigiosa escola de Biologia e Medicina Experimental".

O paralelo com a atitude de Chagas Filho, ao introduzir a nova denominação "laboratório de biofísica" no lugar de "cadeira de física biológica", é justificável. Basta lembrarmos que sua opção pela faculdade era devida, em parte, à provável presença de jovens estudantes interessados na carreira científica, para ali fundar um centro (ou laboratório) de pesquisa e, subsidiariamente, de ensino (Almeida, 2008, p.268). Enquanto na época (segunda metade da década de 1930), a denominação cadeira tinha significado preciso, limitado e - pelo menos na Faculdade de Medicina do Rio de Janeiro - limitante, 
o termo laboratório fazia supor local propício à atividade de pesquisa e indagação, visando à ampliação dos conhecimentos da atualidade. Essa seria a prioridade do laboratório de biofísica 'fundado' por Chagas Filho em 1938.

O problema mais premente a ser resolvido era o da falta de pessoal. Com a promulgação da Constituição Federal de 1937, que proibia a acumulação de cargos, o LB perdera - como de resto as outras cadeiras, em geral - quase todos os assistentes. Esse movimento constitui forte evidência de que o cargo universitário, na quase totalidade dos casos, não representava mais do que fonte de soldo apenas complementar àquele obtido no exercício de outra ocupação, esta sim, a principal. Apenas dois dos assistentes permaneceram no LB: Carlos Feio, porque se encontrava à beira da aposentadoria, e Lafayette Rodrigues Pereira, filho do catedrático anterior e o único a demonstrar real apego ao cargo, que passou a ocupar a posição de monitor (Chagas Filho, 2000, p.87).

Na urgência de resolver o problema, Chagas Filho buscou a cooperação de amigos como Tito Enéas Leme Lopes (1910-1954) e Almir Castro (1910-?) colegas da turma de 1931 da Faculdade de Medicina, que atenderam prontamente ao apelo. Ao mesmo tempo, solicitou e obteve a importante ajuda de Baeta Vianna (1894-1964), catedrático de química fisiológica da Faculdade de Medicina da Universidade de Minas Gerais (UMG). Baeta envioulhe dois de seus assistentes, José Moura Gonçalves (1914-1996) e João Batista Veiga Salles 5 . Com eles veio Oromar Moreira (1907-1986), para o fim específico de preparar sua tese de concurso (Estudos de oxidorredução), com a qual foi aprovado para professor catedrático na UMG. ${ }^{6}$

O quadro de auxiliares foi construído conforme surgia o pessoal interessado, na maioria estudantes de medicina e, mais raramente, de química ou de biologia. ${ }^{7}$ Recém-graduados ou pós-graduados no exterior também eram recrutados. Foram absorvidos à medida que ascendiam em titulação, pelo interesse na atividade de pesquisa, ou ainda por sua inserção na atmosfera de trabalho, proporcionada pela forma de comando de Chagas Filho. Neste último particular, ele estava em companhia de ninguém menos do que o duas vezes premiado (1958 e 1980) com o Nobel de Química Frederick Sanger (1918- ), que afirmava: "Acredito que a qualidade da pesquisa feita num laboratório depende ao extremo da ambiência local" (Sanger, 1988, p.3). Essa qualidade, de importância fundamental, resultava da obediência a um conjunto de regras, comum entre cientistas que eram chefes de equipe já desde o século XIX, pois é dessa época o típico enunciado, feito por Charles-Adolphe Würtz (1817-1884), doutor em medicina e professor de química orgânica na Faculdade de Ciências de Paris, definindo uma equipe de cientistas: "Os cientistas formam um conjunto de trabalhadores que se agrupam ao redor de um mestre. Todos usufruem de seu ensinamento e de seu exemplo, e cada um da experiência de seu vizinho. ... Um laboratório é, portanto, não apenas um refúgio da ciência: é uma escola" (citado em Alter, Testard-Vaillant, 1997). Logo, onde se pesquisa se pratica também o ensino, tal como Chagas Filho pacientemente nos ensinara ao longo do século XX. ${ }^{8}$

No final de 1945, em data próxima à da transformação do laboratório em Instituto de Biofísica, integrante da FNM da UB, a equipe apresentava a composição descrita no Quadro 1.

Surgido o problema da proibição de acumulação de cargos imposta pela Constituição de 1937, a solução ad hoc havia sido a criação do cargo de técnico especializado. O exame 
do Quadro 1 revela que esse cargo foi de fundamental importância para a continuidade do LB e, por extensão, para a criação do próprio IB. Na ausência da carreira de pesquisador, a invenção do técnico especializado, com salários adequados e trabalho em tempo integral, foi eficaz. Resultado de iniciativa pessoal do diretor do Departamento de Administração do Serviço Público (Dasp), Luiz Simões Lopes (1903-1994) foi adotada para atender a Chagas Filho na solução do problema de falta de pessoal que enfrentava (Mariani, 1982, p.201; Chagas Filho, 2000). Haver obtido assim substituição legítima para compensar as perdas de força de trabalho revela o alcance da sua influência. De fato, o fácil acesso ao mais alto nível da administração da educação superior no país e o tratamento diferenciado dado a Chagas Filho são devidos não só à herança do nome deixado por seu pai (capital científico), como também à posição político-social que adquiriu pela união, em 1935, com Ana Leopoldina Mello Franco (capital político-social) (Góes Filho, 1997; Almeida, 2009).

O núcleo de docentes-pesquisadores foi iniciado com a chegada do ainda estudante de graduação Manoel da Frota Moreira (1920-1986). Após sua graduação em medicina (1940) e estágio na Universidade de Harvard (1941-1943), foi ele designado chefe da Divisão de Física Médica e Radiobiologia (1944). Desde cedo aproximou-se de Chagas Filho e passou a auxiliá-lo no trabalho de administração; mais tarde chegaria a ser seu auxiliar mais próximo, como vice-diretor e eventual substituto em ausências mais prolongadas.

José Moura Gonçalves (1914-1996) foi contratado como técnico especializado em 1940 e tornou-se livre-docente de biofísica, primeiro assistente da cadeira e chefe da Divisão de Físico-química Biológica em 1947. Em 1951 deixou o IB ao aceitar o convite de Zeferino Vaz (1908-1981) fundador e diretor da Faculdade de Medicina da USP, em Ribeirão Preto, para assumir a cátedra de bioquímica.

Aristides Azevedo Pacheco Leão (1914-1993), após conquistar os diplomas de Master of Arts (1942) e Doctor of Philosophy (1943) na Universidade de Harvard, ingressou no LB em

\title{
Quadro 1: Pessoal do Laboratório de Biofísica - 1945
}

\author{
Diretor: Carlos Chagas Filho, catedrático de biofísica \\ Livre-docentes de biofísica: Tito Enéas Leme Lopes, técnico especializado; José Moura Gonçalves, tec. esp. \\ Doutor em ciências médicas: Aristides Azevedo Pacheco Leão, tec. esp. \\ Doutores em medicina: Angelo Lobo Machado, tec. esp.; Lafayette Rodrigues Pereira, tec. esp.; Manoel \\ Frota Moreira, tec. esp.; Antonio Moreira Couceiro, voluntário; Pedro Cavalcanti, voluntário; Hiss Martins \\ Ferreira, biologista; Marisa Xavier Oliveira (Musacchio, pelo casamento), biologista; Alberto Barbosa \\ Hargreaves, assistente de ensino \\ Técnica especializada: Hertha Meyer \\ Radiotécnico: Miguel M. Cesar \\ Laboratorista: Laura Gouvea Vieira; e mais um cargo vago \\ Monitor: Osvaldo L. Maior \\ Secretária: Yolanda Machado da Silva \\ Datilógrafas: Maria Gabriela Machado; Maria de Lourdes Silva \\ Serventes: Augusto da Silva; Jorge Castro Lima; Moacyr Eloi Rosa; Heraldo Gallo
}

* Fonte: Ofício de Chagas Filho (s.d.) ao reitor da UB, presumivelmente do final de 1945 (outubro?) (Chagas Filho, 1930-1940). 
1945, como técnico especializado. Passou a chefe da Divisão de Eletrobiologia em 1947. Estabeleceu o laboratório de estudos da "depressão alastrante" - conhecida na literatura internacional como Leão's wave -, descoberta que fez no curso de sua tese de doutorado.

Lafayette Rodrigues Pereira colaborou de início com Chagas Filho no estudo da bioeletrogênese e mais tarde dedicou-se à cadeira de física aplicada à farmácia, na Faculdade Nacional de Farmácia, na qual chegou a catedrático em 1947. Angelo Lobo Machado encontrava-se, nessa época, em estágio de aperfeiçoamento na Universidade de Colúmbia, depois do que tomou rumo ignorado. Antonio Moreira Couceiro (1914-1978), originário do Recife, estagiou por dois anos na USP (neuropatologia), antes de trabalhar como assistente voluntário de Chagas Filho (1945). Chegou ao cargo de chefe da Divisão de Biofísica Celular em 1947, como técnico especializado. Pedro Cavalcanti foi colaborador voluntário durante algum tempo.

Hertha Meyer (1908-1990) chegou para assumir a chefia do Laboratório de Cultura de Tecidos. Duas vezes refugiada da Segunda Guerra Mundial - primeiro, do nazismo, na Alemanha (Kaiser Wilhelm Institut), no distrito de Dahlem, em Berlim; depois, do fascismo, na Itália (Universidade de Turim) -, servia então no laboratório de febre amarela mantido pela Fundação Rockefeller no IOC. Em 1940 transferiu-se para o LB. Ali realizou estudos em miocárdio infectado pelo Trypanosoma cruzi. Ainda nos anos 1940, chegam Hiss Martins Ferreira (1920-2009), com graduação na FNM em 1943, e Marisa de Oliveira Musacchio (FNM, 1944). Tal era o fascínio de Hiss pela experimentação e manipulação dos equipamentos, que dizia ser, por natureza, um 'obreiro' (Ferreira, 10 dez. 2002); ambos eram laboratoristas e biologistas concursados. Hiss trabalhou com Aristides Leão; Marisa logo se associou a Hertha Meyer, no Laboratório de Cultura de Tecidos.

Alberto Barbosa Hargreaves (1916-1984), graduado em 1938, trabalhou inicialmente em clínica particular (análises clínicas) e, nessa condição, em 1939, ingressou no IB como assistente de ensino. Em 1947 assumiu o cargo de biologista. Laura Gouvea Vieira (19172011), laboratorista concursada (1943), exercia essa função no laboratório dirigido por Moura Gonçalves, com quem se casou mais tarde.

Recursos para pagamento de pessoal de várias categorias, instalação e funcionamento dos laboratórios ainda eram 'peça de ficção', praticamente inexistindo entre 1938 e 1945. Vejamos quais foram os movimentos executados por Chagas Filho, nessas circunstâncias.

\section{A obtenção de recursos para a pesquisa científica}

Na ausência de qualquer órgão dirigido para o amparo à pesquisa, Chagas Filho lançou mão de suas relações pessoais e profissionais, o que se comprova quando verificamos que os recursos para aquele fim eram provenientes das mais variadas fontes. A lista que Chagas Filho apresentou, ao publicar o que denominou "uma breve notícia sobre o 'Laboratório de Biofísica', da FNM/UB", é muito significativa. São citados aqueles de quem Chagas Filho recebeu ajuda, apoio ou colaboração, entre 1938 e 1942 (Chagas Filho, 23 nov. 1942).

O texto introdutório ressalta que no "esforço de organizar um laboratório universitário de pesquisas biofísicas, o primeiro passo foi dado graças ao auxílio prestado por Evandro Chagas" (Chagas Filho, 23 nov. 1942, p.1) com o qual foi possível a construção do Laboratório 
de Cultura de Tecidos. (Evandro tinha interesse particular no estudo do miocárdio infectado pelo Trypanosoma cruzi.) Em seguida, apresenta-se a lista das autoridades federais que o apoiaram:

Gustavo Capanema, ministro da Educação e Saúde, Luiz Simões Lopes, presidente do Departamento Administrativo do Serviço Público (DASP), Raul Leitão da Cunha, Reitor da Universidade do Brasil, Álvaro Fróes da Fonseca, Diretor da Faculdade Nacional de Medicina, Mario Bittencourt Sampaio, Diretor da Divisão de Estudos do DASP. Agradece também "o generoso apoio de Guilherme Guinle (1882-1960) (que mais tarde receberia o título de Patrono do IB) e da Fundação Rockefeller obtive a vinda para o Brasil do Professor René Wurmser, que há mais de um ano vem trazendo ao LB a sólida experiência de sua cultura científica.

Nota a colaboração desinteressada do Instituto Oswaldo Cruz, do Instituto Nacional do Cinema Educativo e do Instituto Terapêutico Orlando Rangel. Declara que a cooperação científica recebida dos Professores J. Costa Ribeiro, da Fac. Nac. de Filosofia, Marcelo Damy de Souza Santos e G.P. Occhialini, da Faculdade de Ciências da USP, Gustavo Corção, da Escola Técnica do Exército, Bernhard Gross e F.M. de Oliveira Castro, do Instituto Nacional de Tecnologia, e do Dr. João Machado, foi decisiva (p.1; grifos meus). ${ }^{9}$

A lista, sem dúvida, não é exaustiva. Não estão mencionados os vários parlamentares que apoiaram tanto o LB quanto o IB, como Jorge Jabour (1905-1970), Rui Santos (19021985) e Gabriel Passos (1901-1962), entre outros. Ademais, auxílios devidos à retomada da cooperação técnica internacional depois de 1945 não são aqui referidos por se situar fora do período compreendido por este trabalho. Ainda assim, podemos citar, entre outros organismos, a Fundação Rockefeller, por meio de um de seus diretores, Harry Miller Jr., que atuava no Rio de Janeiro, o Conselho Britânico, o Serviço Cultural do Ministério das Relações Exteriores da França e, mais tarde, com especial relevo, a adida cultural da França no Brasil, madame Gabrielle Mineur.

Desde que ascendeu à cátedra, mas sobretudo após a fundação do IB, Chagas Filho recorreu a relações internacionais para estimular atividades culturais, científicas ou técnicas. O sistema funcionava como via de mão dupla, e o verão (época das férias) definia o anfitrião. Assim, desde o mês de dezembro até o final de nosso verão acontecia, no prédio da FNM, na Praia Vermelha, Rio de Janeiro, o que os alunos denominavam "a revoada dos cientistas do Chagas", com a chegada de inúmeros professores visitantes. Como a 'revoada' tinha caráter bilateral, nos meses de julho a setembro funcionava no sentido inverso, e compreendia a ida não só de nosso pessoal docente/pesquisador - esse era ponto crucial na política de intercâmbio -, mas também de estudantes de graduação. ${ }^{10} \mathrm{O}$ sistema foi recuperado a partir do pós-guerra, com grande e continuado proveito institucional.

A busca de cooperação nacional e internacional exigia de Chagas Filho considerável esforço pessoal, diplomático e científico, além de grande parte de seu tempo. Os resultados obtidos nos parecem compensadores, a julgar pela produção dos Seminários de Biologia, em julho de 1943, em fevereiro-março de 1944 e, mais tarde, em outubro de 1947. Menção especial merece o de 1943, realizado de 2 a 6 de julho no Rio de Janeiro. Dele participaram futuros detentores do prêmio Nobel, Bernardo Houssay (1887-1921) e Luis Leloir (1906-1987), além de figuras de elevado prestígio internacional como o geneticista Theodosius Dobzhansky 
(1900-1975), inspirador primeiro da moderna síntese da genética, em 1937, ao aproximar a genética experimental da sistemática evolutiva e revelar toda a importância da seleção natural em Genetics and the origin of species, de 1937.

Outros presentes eram o casal René e Sabine Wurmser, do IBPC, de Paris, Marcelo Damy de Souza Santos (1914-2009), da Física da USP (que socorreu Chagas Filho com equipamentos, no início de suas atividades experimentais), Thales Martins e Gilberto Vilela, do IOC. A participação do casal Wurmser atesta que sua primeira visita ao Laboratório aonde chegaram em 26 de junho de 1941 - foi bem mais longa do que os alguns meses geralmente mencionados na literatura especializada. E as visitas, recíprocas, repetiram-se numerosas vezes sobre o Atlântico.

No período sob estudo, início de longa jornada, observa-se a intensa atividade de Chagas Filho no meio acadêmico. Sua presença e participação notáveis nas atividades da Academia Brasileira de Ciências levaram-no à posição de membro titular daquela casa, em 1941, por indicação do almirante Alvaro Alberto.

Várias teses, para fins de concursos na carreira universitária, foram elaboradas no LB: a de Oromar Moreira (física biológica), para catedrático da UMG; as de Tito E. Leme Lopes, Oscilografia catódica em biologia, para a Faculdade Fluminense de Medicina (1941), e Alguns estudos sobre a faixa de Soret, para livre-docência na FNM (1942); as de José Moura Gonçalves, Sobre a determinação dos coeficientes de absorção e difusão nas células, para a livre-docência na FNM (1942), e Eletroforese de proteínas, para a cátedra de bioquímica, também na FNM (1951) - esta última jamais foi apresentada, pois em 1951 Moura passou a chefiar a cadeira similar da nova Faculdade de Medicina da USP.

Em 8 de novembro de 1940, com a morte de Evandro Chagas em acidente de avião, Chagas Filho assumiu, a convite do governo federal, o posto de superintendente do Serviço de Estudos das Grandes Endemias (Sege), cargo que exerceu até o final de 1941, para se encarregar da absorção do pessoal do serviço pelo IOC. As anotações em seus diários mostram com muita clareza que a empreitada que enfrentou era bem mais difícil e pesada do que poderia ter imaginado, tanto pelo volume de trabalho quanto por seu acentuado aspecto político.

\section{O final do Estado Novo e a fundação do Instituto de Biofísica da Universidade do Brasil}

O final do Estado Novo já era esperado, e a movimentação política resultante não criava ambiente propício para a redemocratização do país. A alteração proposta para o calendário eleitoral e as nomeações de João Alberto Lins de Barros (1897-1955) para a prefeitura e de Benjamim Vargas (1897-1973) para a chefia da polícia do Rio de Janeiro (Departamento Federal de Segurança Pública), em substituição a João Alberto, trouxeram inquietação aos meios político-militares. Sendo João Alberto fiel amigo de Benjamim, irmão de Getúlio Vargas, o conjunto dessas mudanças foi interpretado pelo poder militar como os primeiros passos para novo golpe político. Logo reagiram a essa ameaça e forçaram Getúlio a renunciar em 29 de outubro (D'Araujo, 2000, p.60-64).

Pouco antes dessas ocorrências, Chagas Filho percebeu que nelas havia séria ameaça a seus planos e resolveu agir no sentido de obter a realização de sua aspiração maior, a 
criação do Instituto de Biofísica da UB, antes que as mudanças se consumassem. Na ocasião, ocupava o cargo de reitor da UB, desde 1937, o professor Raul Leitão da Cunha (18811947). Depois de haver sido seu aluno na graduação de medicina, Chagas Filho tornou-se seu assistente na cadeira de anatomia patológica, de março de 1932 a março de 1934. Desde então, estabelecera-se entre eles firme amizade. Ao se referir à fundação do IB, Chagas Filho em geral relatava diálogo que teria mantido, logo após a queda do Estado Novo, com o ministro da Educação, Leitão da Cunha, que o convocou e perguntou-lhe o que deveria ser feito pela universidade. Respondeu-lhe Chagas Filho que seria estabelecer o tempo integral, sobretudo nas cátedras fundamentais, e a organização de institutos de pesquisa e ensino nas disciplinas básicas. Na mesma conversa, depois de declinar do convite para dirigir um eventual Instituto de Física alegando haver outros professores mais competentes para o cargo, ouviu do ministro a pergunta: "E por você, o que posso fazer?". A resposta veio sem hesitação: "Criar o Instituto de Biofísica, que teria função de implantar a pesquisa na Faculdade de Medicina e trazer para o nosso meio os métodos físicos que despontaram nos centros maiores depois da Segunda Guerra Mundial, e o desenvolvimento dos métodos eletrônicos" (Chagas Filho, 2000, p.93).

A proposta de Chagas foi aceita, e o IB foi criado pelo decreto-lei 8.393, de 17 de dezembro de 1945, que deu autonomia à Universidade do Brasil. Carlos Chagas Filho, entretanto, só tomou posse como diretor em 12 de agosto de 1946. Qual dessas deve ser considerada a real data de fundação do IB? De acordo com informação fornecida no primeiro semestre de 2009 pela colega Maria da Conceição Castro, do Arquivo Nacional e da Casa de Oswaldo Cruz, e segundo a legislação em vigor, a data de fundação de um órgão componente da administração (federal, estadual ou municipal) é a da emissão do respectivo título oficial. A posse tardia não muda essa circunstância; o órgão já havia sido criado e foi deixado vazio, por contingências, necessidades ou imprevistos intervenientes. Nessas condições, 17 de dezembro de 1945 deve ser considerada a verdadeira data de fundação do IB, ainda que não houvesse um diretor empossado.

Outra proposta cobiçada por Chagas Filho para o IB, e das que mais prezava e valorizava, desde quando o Instituto ainda se apresentava sob a forma de projeto em início de desenvolvimento, era a adoção do tempo integral de dedicação, dentro de um sistema multidisciplinar de trabalho. As finalidades do IB estão fixadas em seu regimento, publicado no Diário Oficial de 30 de outubro de 1946, após aprovação pelo Conselho Universitário da UB:

Art. 1으을 Instituto de Biofísica da Universidade do Brasil destina-se à investigação dos problemas da Biofísica e a cooperar no ensino de Biologia, Física Química e Médica, nos vários setores universitários da Universidade do Brasil, bem como no desenvolvimento das atividades culturais, científicas e técnicas da Universidade do Brasil.

§ 1ํA cooperação prevista neste artigo será feita mediante acordo realizado entre o Diretor do Instituto de Biofísica e o professor interessado, sujeito à aprovação do Conselho Universitário (Brasil, 30 out. 1946, p.14646). 


\section{AGRADECIMENTOS}

Mais uma vez contei com o apoio incondicional de Paulo Gadelha, "meu irmão em Chagas", como nos designa Anna Maria Chagas Bovet (Guiguite), terceira filha do casal Chagas Filho. Contei ainda com a valiosa colaboração de Patricia, Catia, Alexandre, e, em casa, Suely. Estes são representantes de muitos outros que ajudaram a tornar o meu trabalho tão agradável: os amigos dos quarto e sexto andares da Expansão, onde funcionam departamentos da Casa de Oswaldo Cruz. Minha sede é o sexto andar, por isso estou sempre mais perto de Francisco, o 'mágico' dos arquivos, Nathacha, Roberto, Rita, Vinicius, Aline, Iracy, Stephany, Conceição e do 'bloco' do 601, Ana Luce e Nara, Camelo ... Imaginem se eu trago o quarto andar para cá... Muito obrigado a todos!

\section{NOTAS}

${ }^{1}$ Nesta e nas demais citações de textos em outros idiomas, a tradução é livre.

${ }^{2}$ Ver, a respeito, Mesquita Filho, 1969, que explicita o conteúdo político-educacional do projeto sob a direção inicial de Armando de Salles Oliveira; Cardoso, 1982; Schwartzman, 1991; Mendonça, 2000; e Campos, 2004, na edição fac-similar de 1954.

${ }^{3}$ Características da UDF, bem como seus objetivos teóricos, e relato dos eventos de natureza política que precederam seu fechamento pelo governo federal podem ser encontrados em Fávero, 1980; Paim, 1981; Teixeira, 1998; e Schwartzman 1979, 1982, 1991.

${ }^{4}$ Detalhes desse percurso podem ser encontrados em Almeida, 2003, p.272-273.

${ }^{5}$ Veiga Salles, depois de curto estágio, transferiu-se para o Departamento de Bioquímica da USP, onde também não se fixou. Entre 1949 e 1950, na qualidade de bolsista, migrou para o Departamento de Farmacologia da Universidade de Nova York, chefiado por Severo Ochoa (1905-1993), prêmio Nobel de Fisiologia ou Medicina, 1959. Veiga Salles morreu em desastre de automóvel, em São Paulo (data ignorada).

${ }^{6}$ Junte-se a isso tudo a limitada experiência do próprio Chagas Filho em atividades didáticas. Ele reporta sua iniciação na "atividade didática superior" a duas ocasiões, mas não parece existir contradição entre elas. Uma delas diz respeito ao curso "Introdução ao estudo da biologia", que ministrou, a convite, em 1932 no Instituto Católico de Estudos Superiores - cujo nome aponta para suas origens.

${ }^{7} \mathrm{O}$ perfil do novo pessoal incorporado ao IB foi alterado com o passar do tempo, devido à presença crescente de especialistas de outras áreas. A mudança foi favorecida pela largueza da visão prospectiva de Chagas Filho e justificada por seu aforismo "Biofísica é tudo que se faz no laboratório" (Almeida, 2009, p.57). Os novos fatos e essa atitude propiciaram o desenvolvimento da multidisciplinaridade no IB.

${ }^{8}$ Bem cabe, a propósito, uma pequena emenda na história da difusão da máxima "na Universidade se ensina porque se pesquisa" (hoje incorporada à bandeira do Instituto de Biofísica Carlos Chagas Filho). Acreditávamos, todos nós, que essa proclamação de Chagas Filho datava da segunda Conferência Geral das Universidades, que teve lugar em Istambul, em 1955. Na verdade, uma investigação mais cuidadosa revelou que o lançamento da máxima ocorreu, sob outras formas, desde 1952 (Chagas Filho, 1952, 1956).

${ }^{9}$ O doutor João Machado foi responsável pela construção do Laboratório de Cultura de Tecidos do LB.

${ }^{10} \mathrm{O}$ sistema bilateral da 'revoada' proporcionou a descoberta de estudantes de graduação com especial interesse pelo assunto trazido por algum visitante. No período seguinte, o estudante interessado, durante suas férias escolares, era levado a frequentar os laboratórios do visitante específico, em estágio. Dessa maneira foram cultivadas as sementes de novos laboratórios na Praia Vermelha, e também na ilha do Fundão, com a chefia honorária do cientista estrangeiro, que aqui retornava regularmente. O estudante noviço, se e quando demonstrada sua competência, na prática, após sua graduação, era alçado ao comando de um laboratório.

\section{REFERÊNCIAS}

ALMEIDA, Alvaro Ozorio de.

Valor da ciência: dificuldades e lutas de minha carreira científica. Cadernos da Sociedade Brasileira para o Progresso da Ciência, São Paulo, n.2, p.10-11. 1950.
ALMEIDA, Darcy Fontoura de.

Carlos Chagas Filho: seus aforismos, marcos na trajetória de sua vida. In: Moraes, Julio Studart de (Org.). Conversas na academia. Rio de 
Janeiro: Editora Fiocruz; Academia Nacional de Medicina. p.53-58. 2009.

ALMEIDA, Darcy Fontoura de.

A opção de Carlos Chagas Filho pela física biológica: razões e motivações. História, Ciências, Saúde - Manguinhos, Rio de Janeiro, v.15, n.2, p.261-275. 2008.

ALMEIDA, Darcy Fontoura de. Carlos Chagas Filho: do curso de graduação à cátedra de física biológica da Faculdade Nacional de Medicina, Universidade do Brasil (1926-1937). Revista Rio de Janeiro, Rio de Janeiro, n.11, p.135-147. 2003.

ALMEIDA, Darcy Fontoura de. The main lines of multidisciplinary research implanted at the Institute of Biophysics by Carlos Chagas Filho. In: The challenges of sciences. A tribute to the memory of Carlos Chagas - Working Group. Annals... Vatican City: The Pontifical Academy of Sciences. p.33-40. (Pontificiae Academiae Scientiarum Scripta Varia, 103). 2002.

ALTER, Anna; TESTARD-VAILLANT, Philippe. Guide du Paris savant. Paris: Belin. 1997.

ARAGÃO, Henrique de Beaurepaire. Notícia histórica sobre a fundação do Instituto Oswaldo Cruz (Instituto de Manguinhos). In: Coura, José Rodrigues; Ferreira, Luiz Fernando; Paraense, Wladimir Lobato (Org.). Centenário do Instituto Oswaldo Cruz, 1900-2000. Rio de Janeiro: Instituto Oswaldo Cruz. Edição fac-similar de artigo publicado em Memórias do Instituto Oswaldo Cruz, Rio de Janeiro, v.48, 1950, p.1-94. 2000.

BRASIL.

Decreto n.14.343, de 7 de setembro de 1920 . Institui a Universidade do Rio de Janeiro. Disponível em: http://www6.senado.gov.br/ sicon/index.jsp. Acesso em: 26 out. 2011. 7 set. 1920.

\section{BRASIL.}

Decreto n.11.530, de 18 de março de 1915.

Reorganiza o ensino secundário e o superior da República. Disponível em: http://www6.senado.gov.br/legislacao/ ListaPublicacoes.action?id=52597\&tipo Documento=DEC\&tipoTexto=PUB. Acesso em: 26 out. 2011. 18 mar. 1915.

BRASIL.

Ministério da Educação e Saúde. Universidade do Brasil. Regimento do Instituto de Biofísica da Universidade do Brasil. Diário Oficial da União, Rio de Janeiro. Seção 1, p.14646-14647. 30 out. 1946.
CAMPOS, Ernesto de Souza.

História da Universidade de São Paulo. São Paulo: Editora da Unesp. 2004.

CARDOSO, Irene de A. Ribeiro.

A universidade da comunhão paulista: o projeto de criação da Universidade de São Paulo.

São Paulo: Autores Associados. 1982.

CHAGAS, Ana Leopoldina de Mello Franco. [Depoimento]. Entrevistador: Darcy Fontoura de Almeida. (Acervo pessoal). 7 out. 2003; 3 out. 2005.

CHAGAS FILHO, Carlos.

Um aprendiz de ciência. Rio de Janeiro: Nova Fronteira; Editora Fiocruz. 2000.

CHAGAS FILHO, Carlos.

[Depoimento]. Rio de Janeiro. Casa de Oswaldo Cruz/Fundação Oswaldo Cruz. 1987-1988.

CHAGAS FILHO, Carlos.

Aula Magna na Faculdade Nacional de Medicina. In: Chagas Filho, Carlos. Homens e coisas da ciência. Rio de Janeiro: Gráfica da Universidade do Brasil. p.9-24. Aula proferida em 1953. 1956.

CHAGAS FILHO, Carlos.

Reflexões sobre a evolução da pesquisa científica no Brasil. Ciência e Cultura, São Paulo, v.4, p.80. 1952.

CHAGAS Filho, Carlos.

Primeira memória sobre o Instituto de Biofísica. Rio de Janeiro: Oficina Gráfica da Universidade do Brasil. 1948.

CHAGAS FILHO, Carlos.

Laboratório de Biofísica Faculdade Nacional de Medicina. Universidade do Brasil. Rio de Janeiro. Divisão de Cooperação Intelectual. Ministério das Relações Exteriores. Rio de Janeiro, Brasil. Cópia. (Acervo pessoal). 23 nov. 1942.

CHAGAS FILHO, Carlos.

Problemas de física biológica. O Hospital, Rio de Janeiro, v.14, n.6, p.937-943. 1940.

CHAGAS FILHO, Carlos.

Entrada na casa. Discurso de posse como catedrático. Fundo Carlos Chagas Filho, cx.82, mç.1, texto n.01 (Casa de Oswaldo Cruz/ Fundação Oswaldo Cruz). 23 nov. 1937.

CHAGAS FILHO, Carlos.

Memorial sobre os títulos e atividades didáticas, apresentadas ao Conselho Técnico-

Administrativo, para inscrição no concurso ao cargo de professor catedrático de física biológica. Fundo Carlos Chagas Filho, cx. 3, 
mç. 14 (Casa de Oswaldo Cruz/Fundação Oswaldo Cruz). 30 set. 1936.

CHAGAS FILHO, Carlos.

Introdução ao estudo da biologia. Curso ministrado a convite no Instituto Católico de Estudos Superiores. Fundo Carlos Chagas Filho (Casa de Oswaldo Cruz/Fundação Oswaldo Cruz). 1932.

CHAGAS FILHO, Carlos.

Correspondência (incompleta) de Chagas Filho. Arquivos da Faculdade Nacional de Medicina/Universidade do Brasil; cópias digitalizadas. Fundo Carlos Chagas Filho (Casa de Oswaldo Cruz/Fundação Oswaldo Cruz). 1930-1940.

CUNHA, Luiz Antonio.

A universidade temporã: o ensino superior, da colônia à era Vargas. 3. ed. rev. São Paulo: Editora Unesp. 2007.

D'ARAUJO, Maria Celina.

O Estado Novo. Rio de Janeiro: Jorge Zahar. 2000.

FÁVERO, Maria de Lourdes de A.

Universidade \& poder: análise crítica/ fundamentos históricos, 1930-1945. Rio de Janeiro: Achiamé.

FERREIRA, Hiss Martins.

[Depoimento]. Entrevistador: Darcy Fontoura de Almeida. (Acervo pessoal). 10 dez. 2002.

GÓES FILHO, Paulo.

O Brasil no biotério: o Instituto de Biofísica Carlos Chagas Filho e um jeito brasileiro de fazer ciência. Dissertação (Mestrado) - Museu Nacional, Universidade Federal do Rio de Janeiro, Rio de Janeiro. 1997.

KUHN, Thomas S.

The structure of scientific revolutions. Chicago: The University of Chicago Press. 1962.

MARIANI, Maria Clara.

O Instituto de Biofísica da Universidade Federal do Rio de Janeiro. In: Schwartzman, Simon (Org.). Universidades e instituições científicas no Rio de Janeiro. Brasília: CNPq. p.199-208. 1982.
MENDONÇA, Ana Waleska P.C.

A universidade no Brasil. Revista Brasileira de Educação, Rio de Janeiro, n.14, p.131-150. 2000.

MESQUITA FILHO, Julio de.

Política e cultura. São Paulo: Livraria Martins. 1969.

PAIM, Antonio.

A UDF e a ideia de universidade. Rio de Janeiro: Tempo Brasileiro. 1981.

SANGER, Frederick.

Sequences, sequences and sequences. Annual

Review of Biochemistry, Palo Alto, v.57, p.1-28. 1988.

\section{SÃO PAULO.}

Decreto n.6.283, de 25 de janeiro de 1934. Cria a Universidade de São Paulo e dá outras providências. Disponível em: http:// leginf.uspnet.usp.br/criacao/decreto6283.htm. Acesso em: 26 out. 2011. 25 jan. 1934.

SCHALL, Virginia.

Contos de fatos: histórias de Manguinhos. Rio de Janeiro: Editora Fiocruz. 2001.

SCHWARTZMAN, Simon.

A space for science: the development of the scientific community in Brazil. Philadelphia: The Pennsylvania State University. 1991.

SCHWARTZMAN, Simon (Org.).

Universidades e instituições científicas no Rio de Janeiro. Brasília: CNPq. 1982.

SCHWARTZMAN, Simon (Org.).

Formação da comunidade científica no Brasil. São Paulo: Nacional; Rio de Janeiro: Financiadora de Estudos e Projetos. 1979.

TEIXEIRA, Anísio.

A função das universidades. In: Teixeira, Anísio. A universidade de ontem e de hoje. Org. e introd., Clarice Nunes. Rio de Janeiro: EdUerj. p.81-102. 1998.

UFRJ.

Universidade Federal do Rio de Janeiro A Ufrj: história. Disponível em: http:// www.ufrj.br/pr/conteudo_pr.php?sigla= HISTORIA. Acesso em: 27 ago. 2010. s.d.

\section{$\rightarrow \rightarrow \leftrightarrow \leftrightarrow<$}

